\title{
Generational Differences in Motivation at Work in Slovakian Small and Medium Sized Companies
}

\author{
Peter Karácsony \\ Department of Economics, Faculty of Economics, University J. Selyeho, Komarno, Slovakia \\ Email: karacsonyp@ujs.sk
}

How to cite this paper: Karácsony, $\mathrm{P}$. (2019) Generational Differences in Motivation at Work in Slovakian Small and Medium Sized Companies. Open Journal of Social Sciences, 7, 182-191. https://doi.org/10.4236/jss.2019.73015

Received: November 4, 2018

Accepted: March 10, 2019

Published: March 13, 2019

\begin{abstract}
Society's aging trend will have an impact on the labor market. Today, more than $50 \%$ of the labor market is made up of members of Generation $\mathrm{X}$ and the Baby Boomer generation. According to some estimates, the number of young people on the labor market will continue to decline. This trend will lead to an increase in demand for young workers, and companies will be competing for them. For this reason, it is crucial for companies to develop a good motivational strategy. The differences between generations are growing, so more and more gaps can be observed between older and younger employees. For companies, it is challenging to create a working environment that can equally meet the needs of different generations. The purpose of my study was to understand and explain the differences in motivational tools used in the workplace between the generations in small and medium sized companies in Slovakia. In my study, I will investigate which motivational tools most influence the generations in the workplace. In my opinion, this will help managers to decide to motivate the different generations to work more effectively.
\end{abstract}

\section{Keywords}

Generations, Management, Motivation, Organization, Slovakia

\section{Introduction}

Different generations have different expectations, ambitions, and approaches to work. Every generation has its own attitudes, behaviors, expectations, habits and motivational levers.

Over the years, interest in the concept of generations has been inspired by many sociologists, philosophers and researchers. Manheim [1] defines a genera- 
tion as a group of individuals born within the same historical and sociocultural context, who experience the same formative experiences and develop unifying commonalities as a result.

According to Hansen and Leuty [2], the term generation refers generally to a group of people sharing work experience.

Today, there are many approaches to grouping people. The main aspects of categorization are the years of birth (Table 1). Generally, the characteristics of generations are defined in much the same way, and differences can be found in determining the time interval. Today's labor market is made up of employees that belong to the Baby Boomer generation, Generation X, Generation Y and Generation Z.

The Traditionalists/veteran generation includes those born between 1925-1945, individuals who are now mostly grandparents in the family and are no longer active members of the labor market. They grew up during the wars of the mid-20th century, and thus learned how to survive. In the midst of those political changes and a global crisis, the key to surviving was adaption. Many of them worked in the same workplace all their lives. In the working environment, the presence of a target-conscious leader was important for them. The members of this generation, whose main approaches in business are "work hard", "work to live" and "work comes before pleasure", tend to work a lot [3].

The baby boom generation was born between 1946 and 1964, and represented a demographic explosion. They were born after the Second World War, and were thus influenced by enormous development. The members of this generation, also called the "me generation", are described as individualistic and selfish. One main characteristic of this generation is that they are optimistic and duty-conscious workers who are uncomfortable with conflict [4].In the workplace, it is important for them to find new ways as they consciously build their careers. The baby boom generation is an important part of society as it has rich experience and knowledge [5]. Zemke, Raines, and Filipczak [6] posit that the boomers developed a number of core values from their upbringing and their surroundings: optimism, team orientation, personal gratification, health and wellness, personal growth, youth, work, and involvement.

Members of Generation X were born between 1965 and 1979. Herley [7] states that their assets are adaptability, independence and creativity, and that they are unintimidated by authority. Workplace status and salary play very important roles in their lives, and they are very ambitious. Today, they are in the middle of their careers or at the peak. Their relationship systems are typically strong, not just in virtual media. They are not opposed to working hard, but tend to reject

Table 1. Chronological generation classification.

\begin{tabular}{ccccccc}
\hline & Traditionalists & Baby-boom & Generation X & Generation Y & Generation Z & $\begin{array}{c}\text { Generation } \\
\text { Alpha }\end{array}$ \\
\hline Born & $1925-1945$ & $1946-1964$ & $1965-1979$ & $1980-1994$ & $1995-2010$ & $2011-$ \\
\hline
\end{tabular}


hierarchy. They prefer flexible working environments and are open to inventing new things.

For Generation Y, digital culture comes naturally. They were born in the early 1980s, and their technological know-how is already much higher than that of any other previous generation. They grew up with computers, are thus almost "technology crazy". They were influenced by globalization, climate change, technological changes, and Facebook. For them, it is very important to have success, self-determination and self-fulfillment. Their personal goals are the most important, and if they cannot fulfill them at their workplace, they leave the organization. The members of this generation are not willing to fight hard for success, and they want an automatically successful career and high pay. They also want rapid career building and self-realization [8].

The term Generation $\mathrm{Z}$ or the "net generation" is used for the generation born between 1995 and 2010. For this generation, the digital world and the internet are already natural concepts, and they know much more about the world than the previous generations. According to Csehné et al. [9] the factors influencing Generation $\mathrm{Z}$ are career opportunities, a high salary, useful work, flexible working hours and innovation.

The Alpha generation is the generation born after 2010. They are or will be the children of Generation X, Generation Y and Generation Z. This age group is already a social layer which can access education, entertainment and information with one click. Future prognosis says that the Alpha generation will be a generation of entrepreneurs. It will be difficult to work with them and to understand them, because they will spend only limited time in personal conversation [10].

To be successful, today's organizations need to focus more on transforming their working environments to motivate their employees to engage in behavior that is consistent with their goals [11]. Motivated employees are strategically important for companies, and motivating employees is a vital part of being a manager since it is difficult to compete only on the basis of the usual resources of competitiveness like access to capital, technology and natural resources [12].

According to Latham and Pinder [13], workplace motivation is made up of a set of energetic forces that originate both within and beyond an individual's being which initiate work-related behavior and determine its form, direction, intensity, and duration.

The most well-known and commonly accepted motivation theories in business literature are those of Maslow, McGregor and Herzberg. Maslow suggested that there are five needs systems which account for most of our behavior, and he placed these needs in a hierarchy. This theory states the order in which needs will be satisfied based on importance [14].

According to Herzberg [15], motivation develops from the challenge of the job itself through responsibility, achievement, recognition, advancement, and growth. The theory has separated employees' motivation factors into extrinsic and intrinsic factors. Extrinsic Factors, also known as job context factors, are ex- 
trinsic satisfactions granted to employees by other people [16].

Theory $\mathrm{X}$ asserts that employees are inherently lazy and must be coerced by management to work. On the other hand, Theory Y states that people possess the desire to work and will seek out responsibility [17].

The researchers have found that there are three main needs that are highly important for individuals in organizational settings: achievement, affiliation and power [18].

Adams [19] formulated the equity approach as an appropriate mode of effective supervision as well as an important means of ensuring the motivation of workers. Workers tend to believe in it if the organizational reward system is fair. This theory assumes that people want to be treated fairly, and that they tend to compare their contributions and rewards to those received by others.

Locke [20] introduced the goal setting approach, which posits that the intention to work towards a goal is a major source of work motivation.

According to Ballentine et al. [21], managers are constantly searching for ways to create a motivational environment where employees work at their optimal levels to accomplish company objectives. Financial and non-financial incentives vary in their roles, effectiveness, and appropriateness, depending on the type of incentive. Financial motivators include profit sharing, project bonuses, stock options and scheduled bonuses [22]. The purpose of non-financial motivators is to reward employees for excellent job performance, and include flexible work hours, training, and a pleasant work environment [23].

\section{Methodology}

In my research, I was looking for answers to the question of how different generations can be motivated. My primary research was carried out using a quantitative research method using a questionnaire, which is one of the most commonly used research and information gathering techniques. The questionnaire is highly standardized since all questions are the same and the question order does not change.

In my questionnaire, I preferred closed-type questions. Based on the results of the test questionnaire, I made the final changes to the questionnaire and prepared the final question series. My target group incorporated a wide range of subjects, and I tried to reach every possible generation to compare the differences between them. The data analyzed in my paper was collected through a survey conducted between 2015 and 2018 in 17 Slovakian organizations. 850 questionnaires were sent out and 552 questionnaires were returned, representing a return rate of $64.9 \%$. During my research, I examined the characteristics of different generations and their relationship with work.

Based on these, I defined my research hypotheses as follows:

1) The Baby Boomer generation can be expected to demonstrate the highest loyalty. I believe they are unlikely to change their workplace for better working conditions or higher pay. Their motivating factor is long-term work because 
they slowly reach the end of their career. They are inflexible during working hours: they do not like overtime, so flexible working methods are not attractive to them.

2) Generation $X$ employees respect their leaders. They like flexible working hours which, besides their salary, is an important motivational tool for them. Personal career advancement and recognition are also important for them.

3) Generations $Y$ and $Z$ are more flexible than Generation $X$. Commitment to the workplace is less important for them, and better financial conditions and working conditions can drive them to search for a new job. High pay is highly motivating for them, and they aim to achieve leadership levels within their organizations as soon as possible.

The data has been analyzed and processed using Statistical Package for the Social Sciences (SPSS).

\section{Results and Discussion}

The demographic information of the sample is given in Table 2, which shows the gender distribution of Male (72\%) and Female (28\%), which highlights the predominance of male employees within small and medium sized firms. The generation distribution of the respondents was Generation Z (8.5\%), Generation Y (45.6\%), Generation X (31.5\%) and Baby Boomers (14.4\%).

In the survey, I examined which motivational factors affect the different generations. I have shown these results by graphs. In Figure 1, I compared the most important motivational tools. According to the figure, motivational tools differ significantly across generations. In the questionnaire, respondents could mark several motivational factors. The results are expressed as a percentage within each generation.

Table 2. Demographic information of the sample.

\begin{tabular}{cccc}
\hline & Description & Frequency & Percent \\
\hline \multirow{2}{*}{ Age } & Generation Z & 47 & 8.5 \\
& Generation Y & 252 & 45.6 \\
& Generation X & 174 & 31.5 \\
& Baby-boom & 79 & 14.4 \\
\hline \multirow{2}{*}{ Gender } & Male & 397 & 72 \\
& Female & 155 & 28 \\
\hline \multirow{2}{*}{ Education level } & Elementary school & 24 & 4.3 \\
& Intermediate & 101 & 18.1 \\
& High school & 298 & 54.2 \\
& University degree & 129 & 23.4 \\
\hline Position & Worker & 406 & 73.5 \\
& Manager & 103 & 18.7 \\
& Top manager & 43 & 7.8 \\
\hline
\end{tabular}




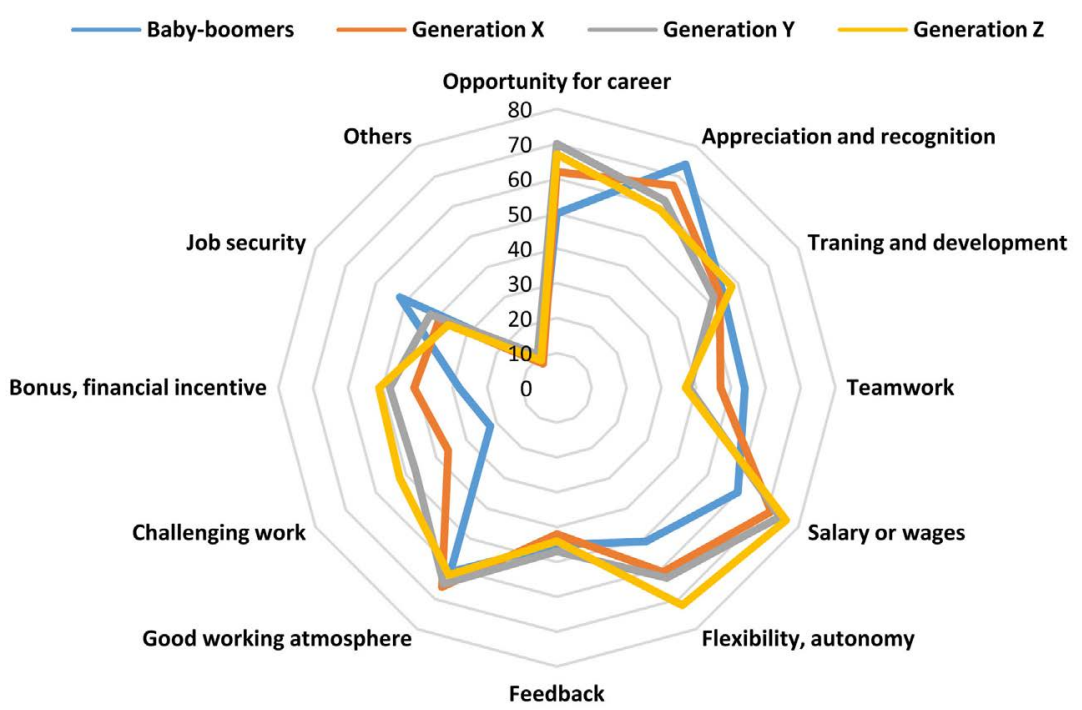

Figure 1. Main motivators of the generations, percentage.

The Baby Boomer generation in the evaluated organizations is primarily motivated by appreciation and recognition (74\%). I surmise that the older generations had reached the peaks of their careers, and therefore did not desire challenging work (22\%) or better career opportunities (50\%), while salary as a motivational tool was moderate (60\%).

By contrast, Generation $\mathrm{X}$ is strongly motivated by financial motivational tools: high salary motivated $71 \%$ of respondents, while the least motivational tool for them was job security (39\%).

Generation Y is highly motivated by salary (74\%), and they look for higher pay and rapid career advancement (70\%). For them, the least motivational tool is the opportunity for teamwork (38\%).

Generation Z, the youngest generation, is most concerned with salary (76\%), while they are less interested in job security (36\%) because they do not think in the long-term.

When asked to respond to the question, "It is important for me to earn more money by overtime in my workplace", only the Baby Boomer generation chose more free time $(74 \%)$, while for the other generations overtime with extra pay was the motivating factor (Figure 2).

I was also interested in how important workplace flexibility was for the respondents (Figure 3).

Based on the answers, I can argue that flexibility is the most important for members of Generation Z (36\%), while flexible work and greater freedom of work time is least important for the Baby Boomer generation (15\%).

According to the data in Table 3, there is a strong (.521) correlation between working conditions and employee satisfaction. In my opinion, to increase employee satisfaction, the leaders should pay more attention to creating a better workplace atmosphere in which the creation of a favorable organizational culture can be of great help. 


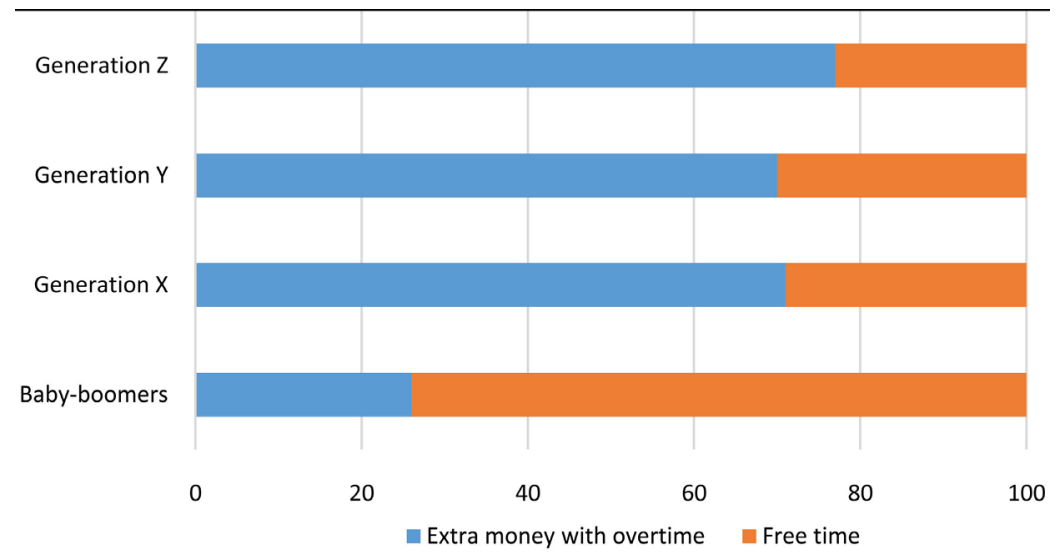

Figure 2. It is important for me to earn more money by overtime in my workplace, percentage.

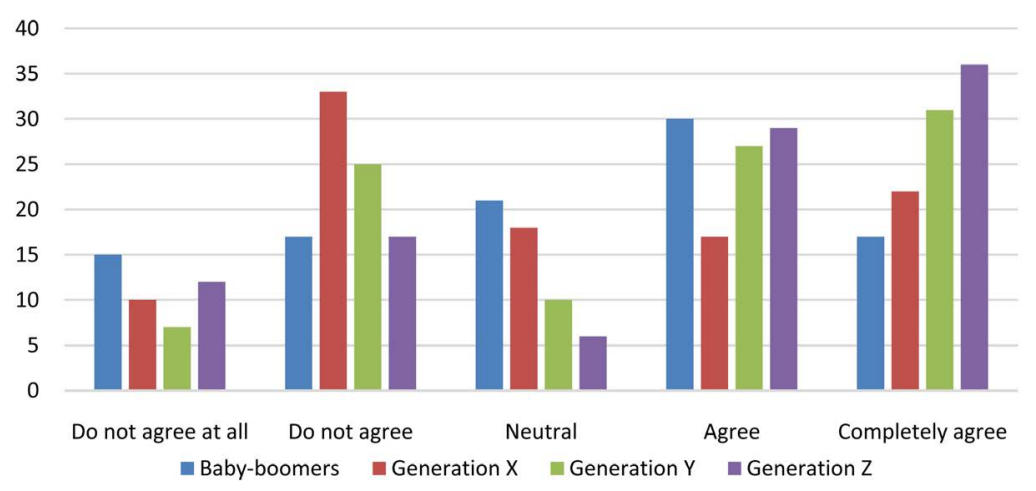

Figure 3. Importance of the flexibility in workplace, percentage.

Table 3. Correlations between working environment and employee satisfaction.

\begin{tabular}{cccc}
\hline & & Working environment & Employee satisfaction \\
\hline \multirow{2}{*}{ Working environment } & Pearson Correlation & 1 & $0.521^{\star *}$ \\
& Sig. (2-tailed) & & 0.000 \\
& $\mathrm{~N}$ & 552 & 552 \\
& Pearson Correlation & $0.521^{* *}$ & 1 \\
Employee satisfaction & Sig. (2-tailed) & 0.000 & 552 \\
& $\mathrm{~N}$ & 552 & \\
\hline
\end{tabular}

${ }^{* *}$ Correlation is significant at the 0.01 level (2-tailed).

\section{Conclusions}

The aim of my study was to highlight the differences between the workplace motivations of different generations. During my research, I presented the characteristics of generations and their workplace attitudes.

In my opinion, every generation is a useful member of an organization. A company works well when every generation is represented and they can work together properly and learn from each other.

My research demonstrates that there are five factors (Figure 4) by which we can motivate generations: favorable working environment, financial incentives, 


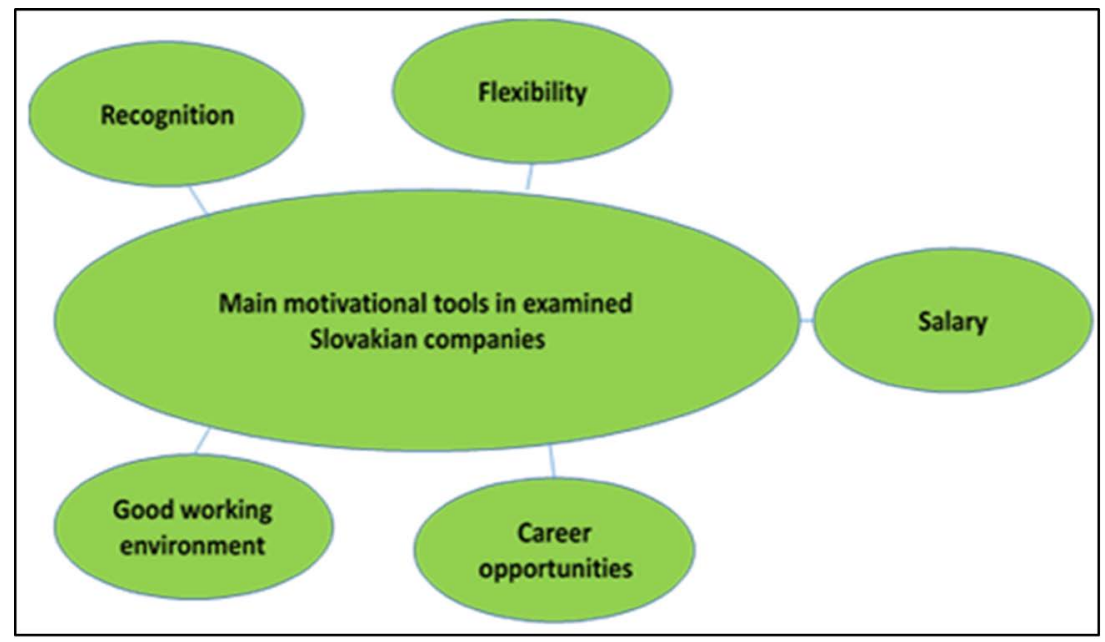

Figure 4. Model for motivation in small and medium-sized companies.

recognition, opportunity for career and flexibility. For generations $\mathrm{Y}$ and $\mathrm{Z}$, leaders will have the task of fully supporting personal development and flexible working time. In terms of personal development, it may be motivating to discuss a target agreement and a possible development path with the employee. In the case of flexible work, it is advisable to introduce alternative employment opportunities such as working from home. For older generations (Baby Boomers and Generation X), recognition and favorable working conditions, including good working relationships, are the main motivating tools.

An important note here is that the motivational tools are not effective individually: only in complex use are they successful in motivation.

Nowadays, a valuable workforce is not enough on the labor market, which is why companies have a long-term interest in workforce retention. It is important for managers to be aware of different generational characteristics, both in general and in motivation factors. By doing so, the leader has to build an incentive system in which most employees can find and keep their motivation, thus avoiding continuous fluctuation.

\section{Acknowledgements}

The publication was prepared with the financial support of Pallas Athéné Domus Educationis Foundation.

\section{Conflicts of Interest}

The author declares no conflicts of interest regarding the publication of this paper.

\section{References}

[1] Mannheim, K. (1952) Essays on the Sociology of Knowledge. Routledge \& Kegan Paul, London.

[2] Hansen, J.C. and Leuty, M.E. (2012) Work Values Across Generations. Journal of 
Career Assessment, 20, 34-52. https://doi.org/10.1177/1069072711417163

[3] Berkup, S.B. (2014) Working with Generations X and Y in Generation Z Period: Management of Different Generations in Business Life. Mediterranean Journal of Social Sciences, 5, 218-229. https://doi.org/10.5901/mjss.2014.v5n19p218

[4] Mangelsdorf, M. (2015) Von Baby Boomer bis Generation Z. GABAL Verlag $\mathrm{GmbH}$, Offenbach.

[5] Otto, C. and Remdisch, S. (2015) Rekrutierung in einerzukunftsorientierten Arbeitswelt. Springer, Hamburg.

[6] Zemke, R., Raines, C. and Filipczak, B. (1999) Generations at Work: Managing the Clash of Veterans, Boomers, Xers, and Nexters in Your Workplace. AMACOM Books, New York.

[7] Herley, W. (2009) Motivating the Generations: Economic and Educational Influences. Journal of Inquiry and Action in Education, 3, 1-14.

[8] Twenge, J., Campbell, S., Hoffman, B. and Lance, C. (2010) Generational Differences in Work Values: Leisure and Extrinsic Values Increasing, Social and Intrinsic Values Decreasing. Journal of Management, 36, 1117-1142.

https://doi.org/10.1177/0149206309352246

[9] Csehné Papp, I., Szabó, K., Schwarczová, L. and Hajós, L. (2017) Expectations and Visions of "Z" Generation of University Students in Relation to the Labour Market. Acta Oeconomica UniversitatisS elye, 6, 23-38.

[10] Schwabel, D. (2014) 5 Predictions for Generation Alpha. http://danschawbel.com/blog/5-predictions-for-generation-alpha

[11] Amar, A.D. (2004) Motivating Knowledge Workers to Innovate: A Model Integrating Motivation Dynamics and Antecedents. European Journal of Innovation Management, 7, 89-101. https://doi.org/10.1108/14601060410534366

[12] Kumar. S. (2011) Motivating Employees: An Exploratory Study on Knowledge Workers. South Asian Journal of Management, 18, 6-47.

[13] Latham, G. and Pinder, C. (2005) Work Motivation Theory and Research at the Dawn of the Twenty-First Century. Annual Review of Psychology, 56, 485-516. https://doi.org/10.1146/annurev.psych.55.090902.142105

[14] Maslow, A.H. (1948) Some Theoretical Consequences of Basic Need-Gratification. Journal of Personality, 16, 402-416. https://doi.org/10.1111/j.1467-6494.1948.tb02296.x

[15] Herzberg, F. (1976) One More Time: How Do You Motivate Employees? Job Satisfaction. A Reader, 17-32.

[16] Robbins, P.S. (2009) Organizational Behavior: International Version. 13th Edition, Pearson Higher Education.

[17] McGregor, D. (1972) An Uneasy Look at performance Appraisal. Harvard Business Review, 50, 133-138.

[18] McClelland, D.C. (1988) Human Motivation. Cambridge University Press. https://doi.org/10.1017/CBO9781139878289

[19] Adams, J.S. (1965) Inequity in Social Exchange. In: Berkowitz, L. Ed., Advances in Experimental Social Psychology, Academic Press, New York. https://doi.org/10.1016/S0065-2601(08)60108-2

[20] Locke, E.A. (1968) Toward a Theory of Task Motivation and Incentives. Organizational Behaviour and Human Performance, 3, 157-189. https://doi.org/10.1016/0030-5073(68)90004-4

[21] Ballentine, A., McKenzie, N., Wysocki, A. and Kepner, K. (2009) The Role of Mon- 
etary and Non-Monetary Incentives in the Workplace as Influenced by Career Stage. Institute of Food and Agricultural Sciences, University of Florida, Gainesville.

[22] Wright, P.L. (1991) Motivation in Organizations. Analyzing Organizational Behaviour, 77-102. https://doi.org/10.1007/978-1-349-21542-3_5

[23] Karácsony, P. (2017) The Analyze of the Employee's Motivation Methods in Environmentally Friendly Organizations. International Journal of Ecology and Development, 32, 119-128. 